\begin{tabular}{l|l|l|l}
$\begin{array}{l}\text { Case Reports in } \\
\text { Demiliatology }\end{array}$ & $\begin{array}{l}\text { Case Rep Dermatol 2010;2:177-182 } \\
\text { DOI: 10.1159/000321635 }\end{array}$ & $\begin{array}{l}\text { Published online: } \\
\text { October 21, 2010 }\end{array}$ & $\begin{array}{l}\text { O 2010 S. Karger AG, Basel } \\
\text { ISSN 1662-6567 } \\
\text { www.karger.com/cde }\end{array}$ \\
\hline
\end{tabular}

\title{
A Case of Cutaneous Nocardiosis with Involvement of the Trachea, Anterior Mediastinum and Sternum
}

\author{
Xiaoyun Wang ${ }^{\text {a Tao Zhou }}{ }^{\mathrm{b}}$ Danqi Deng ${ }^{\mathrm{a}}$ Yun Guo ${ }^{\mathrm{a}}$ \\ Departments of a Dermatology and ${ }^{b} \mathrm{Clinical}$ Laboratory, Second Affiliated Hospital \\ of Kunming Medical University, Kunming, China
}

\section{Key Words}

Cutaneous nocardiosis - Nocardia infection - Bacterial culture -16s rRNA - Nocardia ninae

\begin{abstract}
Nocardiosis is a rare infectious disease due to Nocardia infections. In this report, we present a rare case of cutaneous nocardiosis with involvement of the trachea, anterior mediastinum and sternum. The strain of Nocardia has been isolated from bacterial culture of infected tissue. 16s rRNA sequencing confirmed that it contained the Nocardia genus. The patient was successfully treated with Co-SMZ.
\end{abstract}

\section{Introduction}

Usually, nocardiosis is a rare infectious disease due to Nocardia infections, but there are an increasing number of reports on nocardiosis. It is commonly seen in persons with a compromised immune system. Cutaneous nocardiosis generally occurs in immunocompetent hosts. The diagnosis of nocardiosis is often based on pathology and bacterial culture. However, not every case cultivates a Nocardia. Here, we present a rare case of cutaneous nocardiosis with involvement of the trachea, anterior mediastinum and sternum. The strain of Nocardia has been isolated from bacterial culture of infected tissue. 16s rRNA sequencing confirmed that it contained the Nocardia genus.

\section{Case Presentation}

A 36-year-old woman, farmer by occupation, presented to the Department of Dermatology of the Second Affiliated Hospital of Kunming Medical University with a 10-year history of gradually enlarging and infiltrating painless papulo-nodular lesions of the neck-chest and with complaints of coughing during the last month. Approximately 10 years prior to the visit, the patient experienced a minor trauma on the neck-chest while picking tea in the mountains. Weeks later, a painless red papule 
appeared in the same area. The papule slowly increased in size and became a nodule and abscess that discharged white and yellowish thick granular pus. Over years, multiple recurrent abscesses and sinuses developed around the same area. Occasionally, minute dark granules could be seen in the sinus drainage. The patient began to cough without phlegm and felt a foreign body sensation in the throat one month before the examination. The past medical history of the patient included hypertension.

On physical examinations, we found a $10 \times 25-\mathrm{cm}$ firm, non-tender swelling with multiple superficially eroded, erythematous nodules and plaques with sinus tracts draining purulent discharge on the neck-chest and on her shoulders. The overlying skin was adherent and scarred in some areas (fig. 1). No superficial lymphadenopathy was noted. The patient was initially diagnosed as having tuberculosis or actinomycosis.

The laboratory examinations of the patient were as follows: (1) routine hematological and biochemical tests showed no abnormal findings; (2) ELISA test for HIV and VDRL test for syphilis were both non-reactive; (3) skin purified protein derivative (PPD) test for tuberculosis was negative, and (4) Hepatitis B and C serologies were negative.

Chest X-ray and abdominal Echo-scan revealed no abnormal findings. Spiral CT showed: the lower segment of the neck, the root of the neck to the anterior mediastinum with multiple masses surrounding the trachea and tracheal stenosis at the thoracic inlet section, manubrium of sternum bone destruction and absorption, neck skin thickening, the root of the neck to the front chest, the subcutaneous fat of the root of the neck to the front chest was fuzzy, pairs of cable under the shadow of the pulmonary fibrosis, and adjacent pleural thickening (fig. 2).

A lesional biopsy showed multiple abscesses in the dermis with the presence of abundant neutrophils, plasma cells, lymphocytes, and macrophages. Numerous irregularly lobulated basophilic granules surrounded by closely attached neutrophils were observed (ig. 3 ).

Aerobic culture of the biopsied tissue specimens showed the growth of Nocardia species at $25^{\circ} \mathrm{C}$ in Sabouraud's medium after one week. Nocardia bacteria colonies did not grow at $37^{\circ} \mathrm{C}$ after one week. Gram stain slide of colonies showed Gram-positive branching hyphae.

A phylogenetic tree, based on 16S rRNA gene sequences, showed the relationships of this strain and species belonging to the Nocardia genus. This tree was constructed using the neighbor-joining method. Streptomyces somaliensis DSM 40738T was used as out-group. Bootstrap values were expressed as percentages of 1,000 replications. The branching is supported by the results from the three algorithms used (bar, 0.01 substitutions per nucleotide position). BLAST online search determined that the strains belonged to the Nocardia genus, with a close phylogenetic relationship to the typical strain Nocardia ninae OFN $02.72 \mathrm{~T}$, with a similarity of $98.1 \%$.

The patient was treated with oral Co-SMZ (each containing sulfamethoxazole $0.4 \mathrm{~g}$ and trimethoprim $0.08 \mathrm{~g} ; 2$ tablets/time, 3 times/day, twice the first dose) for eight weeks and achieved very good improvement with this treatment.

\section{Discussion}

Nocardiosis is an acute or chronic, often disseminated, suppurative or granulomatous infection caused by various aerobic soil saprophytes of the Nocardia genus. Pneumonia is typical, but skin and CNS infections are common. Nocardia is a genus of weakly-staining Gram-positive, catalase-positive, and rod-shaped bacteria. It forms partially acid-fast beaded branching filaments (acting as fungi, but being truly bacteria). It has 85 species totally. Some species are non-pathogenic, and some species are pathogenic (nocardiosis) [1]. Several Nocardia species of the Actinomycetaceae family cause human disease. $N$. asteroides is the most common human pathogen; it usually causes pulmonary and disseminated infections. $N$. brasiliensis most commonly causes skin infection, particularly in tropical climates. Other Nocardia species sometimes cause localized or, occasionally, systemic infections. Nocardiosis occurs worldwide in all age groups, but the incidence is 
higher in older adults, especially in men. Person-to-person spread is rare. Infection takes place via inhalation or by direct inoculation of the skin. Nocardia may also infect the skin through a cut wound, puncture wound, or scratch that occurs while working outdoors or gardening. The skin infections, which may take different forms, are called cutaneous nocardiosis. Occupational exposure to soil, such as in field works, landscaping, and farming, increases the risk of contracting cutaneous nocardiosis.

Cutaneous nocardiosis has a similar clinical presentation to actinomycetoma, cutaneous tuberculosis, atypical mycobacteriosis and deep mycosis. Differential diagnosis should be made with these diseases [2]. In the past, the diagnosis of nocardiosis was often relied on histopathology and bacterial culture of infected tissue. The typical histological appearance is that of a central neutrophilic lobulated abscess that contains a variable number of lobulated granules surrounded by neutrophils, plasma cells, lymphocytes, and macrophages. Nocardia colonies may be smooth and moist, or have a 'mold-like' verrucous grey-white waxy or powdery appearance like aerial hyphae. Nocardia colonies have a variable appearance, but most species appear to have aerial hyphae when viewed with a dissecting microscope, particularly when they have been grown on nutritionallylimiting media. The diagnosis of nocardiosis has remained a challenge until now.

Nocardia bacteria found in bacterial culture are the key to the diagnosis of Nocardiosis, but identification of the Nocardia species by culture is a tedious process and it is advisable to submit multiple clinical specimens for culture because smears and cultures are simultaneously positive in only one-third of infections [3]. Species identification is based on classical biochemical methods. They can be identified by Western blot assay, monoclonal antibodies against $54-\mathrm{kDa}$ circulating antigens of Nocardia, and species specific DNA probing will help in the rapid and definitive diagnosis of nocardiosis. ELISA for serodiagnosis of nocardial infection is also useful [4]. In recent years, the number of recognized clinically relevant Nocardia species has dramatically increased, and the difficulties in determining an accurate identification for many of these isolates by conventional methodologies have been well documented [5-7]. The use of molecular techniques, including restriction endonuclease assays (REA) using amplified portions of both the heat shock protein gene and the $16 \mathrm{~S}$ rRNA gene, has greatly improved the reliability of the identifications of these species on patients $[6,8]$. To date, however, the method that provides the most definitive identification of most Nocardia isolates is sequence analysis of the $16 \mathrm{~S}$ rRNA gene [7]. In many cases, analysis of even a segment of the gene gives sufficient information to allow an accurate identification [9].

In our case, the typical histological appearance showed multiple abscesses in the dermis with the presence of abundant neutrophils, plasma cells, lymphocytes, and macrophages. Numerous irregularly lobulated basophilic granules were observed. Aerobic culture of the biopsied tissue showed white colonies at $25^{\circ} \mathrm{C}$ after one week. There were no bacteria colonies growing at $37^{\circ} \mathrm{C}$ after one week. Gram stain slide of colonies showed Gram-positive branching hyphae. It was demonstrated by $16 \mathrm{~S}$ rRNA gene sequencing that this strain is most closely related to Nocardia ninae OFN 02.72T (98.1\% similarity). Due to the difficulty of identifying Nocardia isolates by phenotypic methods, sequence analysis of the 16S rRNA gene was regarded as the 'gold standard' for the identification of Nocardia isolates to the species level. In recent years, the use of 16S rRNA gene sequencing instruments to distinguish numerous new species of Nocardia is common and many of these cases have been shown to be clinically significant. 
In this report, we presented a rare case of cutaneous nocardiosis with involvement of the trachea, anterior mediastinum and sternum, which is rare and not reported before in medical literature.

We reported this case, after the patient had significantly improved her conditions following eight weeks of oral Co-SMZ treatment (each containing sulfamethoxazole $0.4 \mathrm{~g}$, and trimethoprim $0.08 \mathrm{~g} ; 2$ tablets/time, 3 times/day, twice the first dose). Sulphonamides have been the mainstay of antimicrobial therapy for human nocardiosis [12]. Although the majority of these infections can be treated with sulfonamides, there are in vitro differences in antimicrobial susceptibility among different species, so the accurate diagnosis of different species of clinical isolates can be important for predicting drug responsiveness if sulfonamides cannot be used or prove ineffective [13]. Minocyclines and aminoglycosides, especially amikacin, also have excellent in vitro activity. Minocyclines are considered the second medication choice. Combination therapy with a carbapenem or a third-generation cephalosporin with or without amikacin is generally recommended for severely ill patients or for those with involvement of the central nervous system, in whom mortality is close to $50 \%$ if sulfonamide monotherapy is received [14].

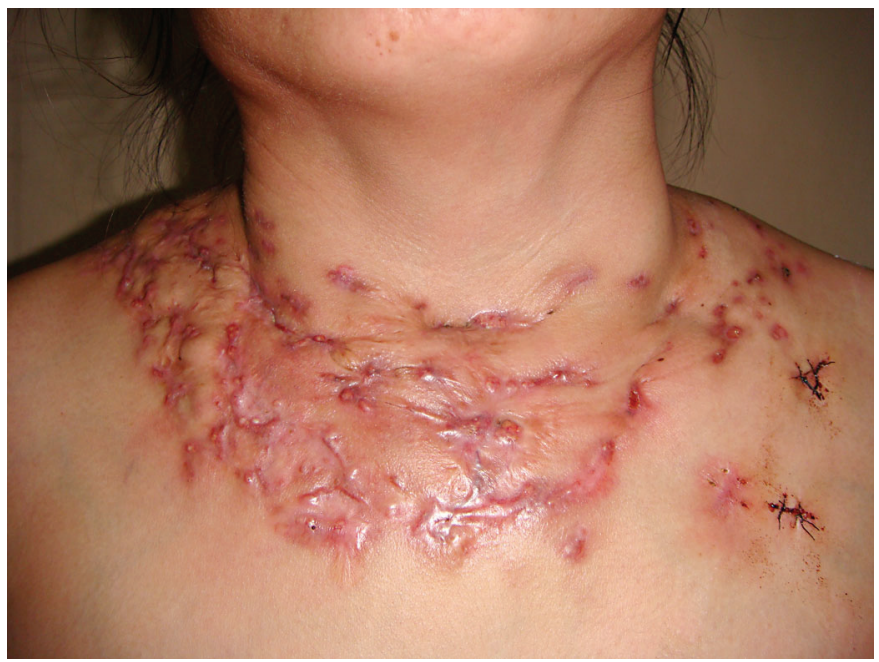

Fig. 1. Firm, non-tender swelling with multiple superficially eroded, erythematous nodules and plaques with sinus tracts draining purulent discharge on the neck-chest and shouders. 


\begin{tabular}{l|l|l|l}
$\begin{array}{c}\text { Case Reports in } \\
\text { Deillatology }\end{array}$ & $\begin{array}{l}\text { Case Rep Dermatol 2010;2:177-182 } \\
\text { DOI: 10.1159/000321635 }\end{array}$ & $\begin{array}{l}\text { Published online: } \\
\text { October 21, 2010 }\end{array}$ & $\begin{array}{l}\text { O 2010 S. Karger AG, Basel } \\
\text { ISSN 1662-6567 } \\
\text { www.karger.com/cde }\end{array}$ \\
\hline
\end{tabular}
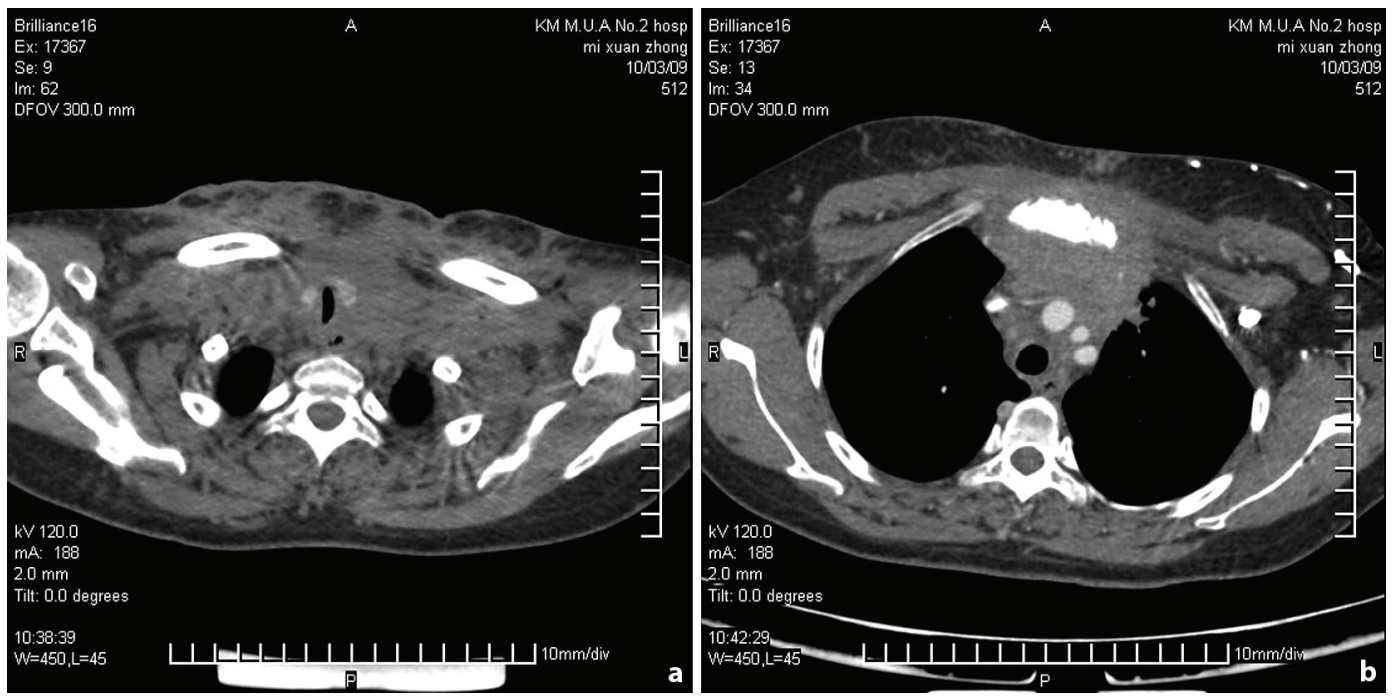

Fig. 2. Spiral CT shows the root of the neck to the anterior mediastinum with multiple masses surrounding the trachea and tracheal stenosis at the thoracic inlet section (a). Manubrium of sternum bone destruction and absorption (b).
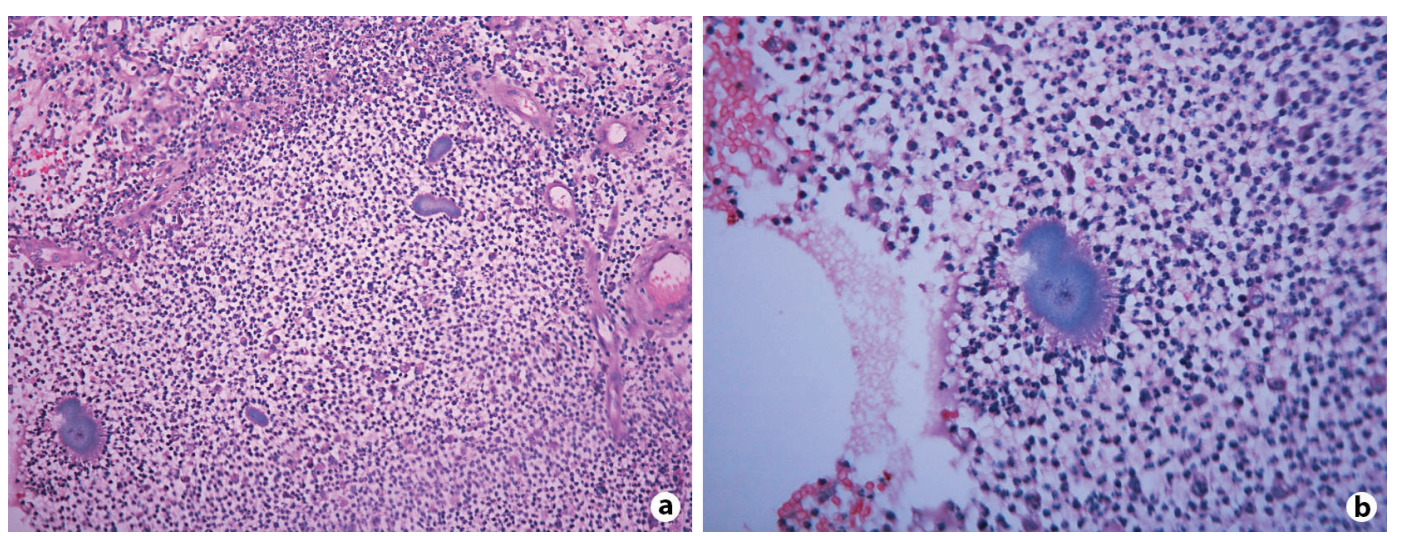

Fig. 3. a Dermal infiltrate of neutrophils, plasma cells, lymphocytes, and macrophages and numerous irregularly lobulated basophilic granules $(\mathrm{HE} \times 200)$. b Sulfur granules $(\mathrm{HE} \times 400)$.

\section{References}

1 Ryan KJ, Ray CG (eds): Sherris Medical Microbiology, ed 4. McGraw Hill, 2004, pp 460-462.

2 Wong YW, Waghorn D, Ratnavel RC: Antibiotic-resistant cellulitis acquired in Turkey. J R Soc Med 2003;96:32-33.

3 Gouveia C, Fraga A, Filipe P, Sequeira H, Boiron P, Couble A, Rodriguez-Nava V, Gomes MM: Mycetoma of the chest wall due to Nocardia brasiliensis. Acta Derm Venereol 2008;88:508-510.

4 Inamadar AC, Palit A: Primary cutaneous nocardiosis: a case study and review. Indian J Dermatol Venereol Leprol 2003;69:386-391.

5 Brown JM, McNeil MM: Nocardia, Rhodococcus, Gordonia, Actinomadura, Streptomyces, and other aerobic actinomycetes: Manual of clinical microbiology, ed 8, ASM Press, 2003, pp 502-531. 
6 Conville PS, Fischer SH, Cartwright CP, Witebsky FG: Identification of Nocardia species by restriction endonuclease analysis of an amplified portion of the 16S rRNA gene. J Clin Microbiol 2000;38:158-164.

7 Roth A, Andrees S, Kroppenstedt RM, Harmsen D, Mauch H: Phylogeny of the genus Nocardia based on reassessed $16 \mathrm{~S}$ rRNA gene sequences reveals underspeciation and division of strains classified as Nocardia asteroides into three established species and two unnamed taxons. J Clin Microbiol 2003;41:851-856.

8 Steingrube VA, Wilson RW, Brown BA, Jost KC, Blacklock, Z, Gibson JL, Wallace RJ: Rapid identification of clinically significant species and taxa of aerobic actinomycetes, including Actinomadura, Gordona, Nocardia, Rhodococcus, Streptomyces, and Tsukamurella isolates, by DNA amplification and restriction endonuclease analysis. J Clin Microbiol 1997;35:817-822.

9 Cloud JL, Conville PS, Croft A, Harmsen D, Witebsky FG, Carroll KC: Evaluation of partial 16S ribosomal DNA sequencing for identification of Nocardia species by using the MicroSeq 500 system with an expanded database. J Clin Microbiol 2004;42:578-584.

10 Conville PS, Brown JM, Steigerwalt AG, Lee JW, Anderson VL, Fishbain JT, Holland SM, Witebsky FG: Nocardia kruczakiae sp. nov., a pathogen in immunocompromised patients and a member of the ' $\mathrm{N}$. nova complex.' J Clin Microbiol 2004;42:5139-5145.

11 Yassin AF, Rainey FA, Burghardt J, Brzezinka H, Mauch M, Schaal KP: Nocardia paucivorans sp. nov. Int J Syst Evol Microbiol 2000;50:803-809.

12 Hornef MW, Gandorfer A, Heesemann J, Roggenkamp A: Humoral response in a patient with cutaneous nocardiosis. Dermatology 2000;200:78-80.

13 McNeil MM, Brown JM: The medically important aerobic actinomycetes: epidemiology and microbiology. Clin Microbiol Rev 1994;7:357-417.

14 Lerner PI: Nocardiosis. Clin Infect Dis 1996;22:891-905. 